\title{
Visceral Leishmaniasis and HIV co-infection in patients admitted to Gondar university hospital, northwest Ethiopia
}

\author{
Getahun Mengistu ${ }^{1}$, Belete Ayele ${ }^{2}$
}

\begin{abstract}
Background: Worldwide, after malaria and sleeping sickness, leishmaniases are the third most important vector borne diseases. Visceral leishmaniasis (kala- azar) is a disseminated protozoan infection caused by L. donovani, $L$. infantum, or L. arachibaldi, and transmitted by the female phlebotomine sand fly bite. Coinciding with HIV infection, the number of visceral leishmaniasis cases in Ethiopia has increased in the last decade.

Objective: To assess the clinical and laboratory manifestations and factors associated with mortality and morbidity of visceral leishmaniasis with or without HIV co-infection.

Methods: A hospital-based case series study of visceral leishmaniasis assessing clinical manifestations, laboratory data, treatment outcomes and HIV sero-status was conducted in Gondar University Teaching Hospital over a period of five years and seven months (from January 1999 to July 2004).

Results: A total of 221 kala-azar patients participated in the study. Out of 212 visceral leishmaniasis cases tested for HIV, 87(41.0\%) were HIV co-infected. Age $>20$ years was independently associated with HIV co-infection. Out of 213 kala-azar patients treated with sodium stibogluconate (SSG), 52 died, resulting in a case fatality rate of $24.4 \%$. The case fatality rates among HIV positive and HIV negative kala-azar cases were $39.3 \%$ and $13.0 \%$, respectively. Using logistic regression, HIV infection, body mass index (BMI) of 15 and below, bleeding tendency, and age $>20$ years were identified as independent variables predicting death.

Conclusion and recommendation: HIV co-infection and the case fatality rates are very high among patients with Visceral leishmaniasis. We recommend further study and improved care for HIV co-infected visceral leishmaniasis cases. [Ethiop.J.Health Dev. 2007;21(1):53-60]
\end{abstract}

\section{Introduction}

Leishmaniases are parasitic diseases caused by obligate intracellular protozoa of the genus leishmania. After malaria and sleeping sickness, leishmaniases are the third most important vector-born diseases accounting for an estimated 1.98 million disability adjusted life years and 57,000 deaths per annum (1).

Leishmaniasis is endemic in 88 countries of five continents: Africa, Asia, Europe, North America and South America, with a total of 350 million people at risk. Worldwide, 12 million people are affected, with or without apparent symptoms. Of the 1.5 to 2 million new cases of leishmaniasis estimated to occur annually, only 600,000 are officially declared (2).

In the past 20 years, the number of human leishmaniasis cases has dramatically increased with a trend that shows no sign of abating (3). This increase might be due to two main factors. The first is the adaptation of the leishmania transmission cycle to peridomestic environments as a response to deforestation and urbanization (4). The other factor is that leishmaniasis is a common opportunistic infection in HIV-infected persons (5).

Visceral leishmaniasis (VL) (kala-azar) is a disseminated protozoan infection, transmitted by sand fly bites, in which macrophages of the liver, spleen and bone marrow are preferentially parasitized with intracellular replication (6). Leishmania donovani is the primary cause of visceral leishmaniasis in the Indian subcontinent and east Africa (7).

Visceral leishmaniasis is characterized by irregular bouts of fever, substantial weight loss, swelling of the spleen and liver, and anemia. If left untreated it is a $100 \%$ fatal illness $(2,8)$. VL is endemic in 62 countries with a total of 200 million people at risk (9). World wide 500,000 new cases of visceral leishmaniasis occur annually, of which $90 \%$ are found in five countries, namely Bangladesh, Brazil, India, Nepal and Sudan (2). There were 41,000 recorded deaths in the year 2000 alone (9).

In Ethiopia, a small outbreak of visceral leishmaniasis was reported among migrant agriculture laborers near the Sudanese border of Northwest Ethiopia in 1978 (10). VL has since been reported from seven of the 16 administrative regions by 1990 (11). Between 1982 and 1990, 149 cases were reported from the Aba Roba focus in the Konso area, South Ethiopia and up to August 1990, a total of 285 cases were recorded by the Institute of Pathobiology in Addis Ababa (11). Coinciding with the HIV epidemic, the burden of visceral leishmaniasis has dramatically increased in Ethiopia over the last 10 years (12-14). In 1996, 7 cases of VL and HIV co-infection were reported (15); in 2002, among $103 \mathrm{VL}$ cases about 51\% were HIV positive (12). Between 1998 and 2000, 839 cases were diagnosed to have VL and out of 213 tested for HIV, 49(23\%) were co-infected in Humera, the Tigray region bordering Sudan and Gondar (16).

HIV/AIDS and VL are locked in a vicious cycle of natural reinforcement, where VL quickly accelerates the onset of AIDS and HIV spurs the spread of VL. AIDS increases the risk of VL by 100-1000 times in endemic areas $(2,17,18$, and 19$)$.

The objective of this study is to assess the clinical and laboratory manifestations and factors associated with mortality and morbidity of visceral leishmaniasis, with or without HIV co-infection. The treatment outcomes will 
be described. To our knowledge, this is the first such large case series hospital-based study in the country, in general, and in Gondar in particular. Moreover, the similarities and differences in the clinical and laboratory manifestations of visceral leishmaniasis with or without HIV co-infections will be described.

\section{Methods}

Study subjects and area: All 221 patients with visceral leishmaniasis diagnosed and or treated in medical wards of Gondar University tertiary level teaching and referral hospital, from January 1999 to July 2004 (5 years and 7 months duration) were included. Gondar University Hospital is located in Gondar town $750 \mathrm{~km}$ Northwest of Addis Ababa. The hospital has 400 inpatient beds and provides health referral services for over 4 million inhabitants in the northwest region of Ethiopia.

Study design and data collection: This is a hospitalbased case series study in the routine care of patients. A pre-tested and standardized questionnaire consisting of demographic data, clinical symptoms and signs, laboratory data, treatment response and outcomes, was used for data collection. In all cases, pre- and post-test counseling was given irrespective of HIV status. Ongoing counseling was arranged for HIV positive patients. A standard dose of sodium stibogluconate (SSG) was administered for 30 days as treatment for VL. Whenever SSG was not available, patients were referred to other treatment centers such as MSF Holland in Humera or Dansha (eight patients). Transport fees and supportive care such as blood transfusion and treatment of intercurrent infections were given.

Diagnosis of VL and HIV: VL diagnosis was made based on clinical parameters and confirmed by spleen or bone marrow aspirations as appropriate. Pathologists and/or senior clinicians read the aspirates at least twice. Wright or Giemsa staining was used as available in the hospital. Direct agglutination test (DAT) with treatment response was used in five cases only, using the methodology and Leishmania donovani test antigen prepared in the Institute of Pathobiology as described by Harith et al (1988). A titer of 1:3200 was used as a threshold cut off value. In all the five cases, the response to treatment with sodium stiboglutinate was dramatic, as the spleen and other symptoms and signs disappeared. All five cases had no other diagnosis or treatment other than the ones for VL. For HIV testing, Determine Abbot Japan and Cappilus - rapid tests and ELISA were used in the hospital. The policy of the department of internal medicine required testing for HIV in all cases of visceral leishmaniasis, in order to anticipate drug toxicity and individualize the care accordingly.

The study included follow up at 3 and 6 months, however participation in the follow up sessions was very low. This is because many of the cases were mobile agriculture laborers or farmers residing far from the hospital and with no permanent address. The follow up sessions also coincided with the rainy and harvesting seasons. Moreover, there was no tracing mechanism in place to actively search for participants for follow up.
Ethical clearance: Informed consent was obtained from all patients and institutional ethical clearance was obtained from the research and publication office of Gondar University.

Operational definitions: Clinical response (initial cure) criteria for successful treatment and discharge from the hospital included disappearance of fever, marked regression of spleen size, significant weight gain, hematological response, and cessation of hemorrhagic diathesis.

Spleen size of $15 \mathrm{~cm}$ and above is defined as a huge splenomegaly, and is associated with infarction, anemia and dragging abdominal pain.

Hematocrit level of $15 \%$ and below is taken as severe anemia with congestive heart failure or pending heart failure that requires transfusion before SSG therapy; hematocrit level of $16 \%$ to $25 \%$ is moderate anemia.

Lymphocytosis is defined as the differential white cell count of lymphocytes more than $50 \%$; granulocytosis is defined as a count of granulocytes above $50 \%$.

Data analysis: Data entry and analysis was performed using Epi Info 2002 and SPPS version 10.0 statistical packages. Logistic regressions were run to determine factors predicting HIV or death. Odds ratios and chi square, with p-value $<0.05$ and a $95 \%$ confidence interval were used for statistical analysis and significance testing.

\section{Results}

From January 1999 to July 2004, there were 8,049 admissions and 1,334 deaths within the medical wards of Gondar University Hospital. Of these, 221 were visceral leishmaniasis cases, accounting for about $2.8 \%$ of the admissions and 52(3.9\%) deaths in the medical wards.

The male to female ratio was 19:1 and the mean age was 25.7 \pm 7.8 years (range 14-55 years). Two hundred and six $(93.2 \%)$ of the cases were under 40 years of age and $119(53.8 \%)$ were in the 20-29 age group, followed by $44(19.9 \%)$ in the $10-19$ age group (Table 1 ).

Of 212(95.9\%) VL patients who agreed to HIV testing, 87(41.0\%) were HIV positive. Of those with both infections, 85(42.3\%) were males. HIV co-infection was found in $65.5 \%(83 / 58)$ of those older than 29 years (Table 1).

With respect to occupational categories, 111(50.2\%) were farmers, 36(16.3\%) were daily laborers, $19(8.6 \%)$ soldiers and 17(7.7\%) students. All of the five civil servants among the study population were HIV positive, as were $90.9 \%(10 / 11)$ of merchants, $63.6 \%(7 / 11)$ of drivers, $63.2 \%(12 / 19)$ of soldiers, $52.8 \%(19 / 36)$ of daily laborers and $29.8 \%$ (31.104) of farmers. One of the nine housewives and two of the 17 students were HIV positive. Seven farmers, one student, and one merchant either did not agree to the HIV test or died before screening (Table 1).

Of the ninety-eight patients from Humera, Abderafi and Dansha area, $43.6 \%$ were HIV co-infected; $34.8 \%$ of the 73 patients from the Metema-Chilga were HIV positive. 
Of the fifty patients from other places in the Amhara region, mainly from North Gondar, $44.9 \%$ were also HIV positive (table 1). Many of these cases had a history of travel to Humera of Metema either recently or some years ago. However, there were a few cases from Belessa and around the Gondar area that had no travel history to Humera. A 14 year old male from Gondar town, sero-negative for HIV, denied any travel out of town in his lifetime.

Of all the VL cases, 87(39.4\%) were seen in 2003, 55 $(24.9 \%)$ in 2002, and a total of $30(13.6 \%)$ in the period between 1999 and 2001. In the seven months of 2004 during which this study was conducted, forty nine (22.1\%) cases were seen. These numbers indicate an increasing trend of VL cases over the years (Figure 1).

Out of 222 total cases, 178(80.5\%) were diagnosed by splenic aspiration, 38(17.2\%) by bone marrow spiration and five (2.3\%) by serum direct agglutination test.
All visceral leishmaniasis patients complained of a history of generalized body weakness. Similarly, all cases had a history of fever with a mean duration and temperature of $12.6 \pm 8.9$ weeks and $38^{0} \mathrm{C} \pm 1^{0} \mathrm{C}$, respectively. Splenomegaly was found in all patients with a mean size of $10.4 \pm 4.5 \mathrm{~cm}$, below the constal margin along the left midclavicular line. Hepatomegaly was seen in 104(47.1\%) patients, with a mean total liver span at right midclavicular line of $14.4 \pm 1.5 \mathrm{~cm}$. A history of weight loss over a mean duration of $13.4 \pm 10.1$ weeks and a mean body mass index of $15.5 \mathrm{Kg} / \mathrm{sq} . \mathrm{m}$ was observed in 218(98.6\%) patients, despite the good appetite reported by 60(27.3\%) patients. About 195(88.2\%) had signs of anemia (pallor), with a mean hematocrit of $22.1 \pm 6.6 \%$. History of bleeding tendency from any site was found in 119(53.8\%) cases; the most common was epistaxis (76.4\% of cases), followed by

Table 1: Sociodemographic characteristics of visceral leishmaniasis patients by HIV serostatus, Gondar University Hospital, 1999-2004.

\begin{tabular}{|c|c|c|c|c|}
\hline Variables & $\begin{array}{l}\text { Total cases } \\
\text { No (\%) }\end{array}$ & $\begin{array}{l}\text { HIV positive } \\
\text { No (\%) }\end{array}$ & $\begin{array}{l}\text { HIV negative } \\
\text { No (\%) }\end{array}$ & $\begin{array}{l}\text { Total screened for } \\
\text { HIV No (\%) }\end{array}$ \\
\hline \multicolumn{5}{|r|}{ 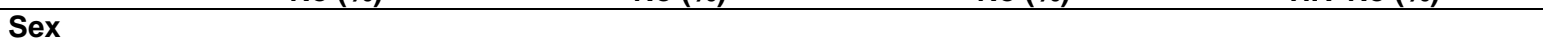 } \\
\hline Male & $210(95.0)$ & $85(42.3)$ & $116(57.7)$ & 201(94.8) \\
\hline Female & $11(5.0)$ & $2(18.2)$ & $9(81.8)$ & $11(5.2)$ \\
\hline \multicolumn{5}{|l|}{ Age interval } \\
\hline $10-19$ & $44(19.9)$ & $5(12.8)$ & $34(87.2)$ & 39(18.4) \\
\hline $20-29$ & $119(53.8)$ & $44(38.3)$ & $71(61.7)$ & $115(54.4)$ \\
\hline $30-39$ & 43(19.5) & $26(60.5)$ & $17(39.5)$ & $43(20.3)$ \\
\hline $40-49$ & $11(5.0)$ & $8(72.7)$ & $3(27.3)$ & $11(5.2)$ \\
\hline 50-59 & $4(1.8)$ & $4(100.0)$ & 0 & $4(1.9)$ \\
\hline \multicolumn{5}{|l|}{ Occupation } \\
\hline Farmer & $111(50.2)$ & $31(29.8)$ & $73(70.2)$ & 104(49.1) \\
\hline Daily laborer & $36(16.3)$ & $19(52.8)$ & $17(47.2)$ & $36(17.0)$ \\
\hline Soldier & $19(8.6)$ & $12(63.2)$ & $7(36.8)$ & $19(9.0)$ \\
\hline Student & $17(7.7)$ & $2(12.5)$ & $14(87.5)$ & $16(7.5)$ \\
\hline Merchant & $12(5.4)$ & $10(90.9)$ & $1(9.1)$ & $11(5.2)$ \\
\hline Driver & 11(5.0) & $7(63.6)$ & $4(36.4)$ & $11(5.2)$ \\
\hline Housewife & $9(4.1)$ & $1(11.1)$ & $8(88.9)$ & $9(4.2)$ \\
\hline Civil servant & $5(2.3)$ & $5(100.0)$ & 0 & $5(2.4)$ \\
\hline carpenter & $1(0.5)$ & 0 & 1 & $1(0.5)$ \\
\hline \multicolumn{5}{|l|}{ Residency } \\
\hline Humera area & $98(44.4)$ & $41(43.6)$ & $53(56.4)$ & $94(44.3)$ \\
\hline Metema area & $73(33.0)$ & $24(34.8)$ & $45(65.2)$ & $69(32.5)$ \\
\hline Other areas & $50(22.6)$ & $22(44.9)$ & $27(55.1)$ & $49(23.1)$ \\
\hline Total & $221(100.0)$ & 84(41.0) & 125(59.0) & 212(100.0) \\
\hline
\end{tabular}

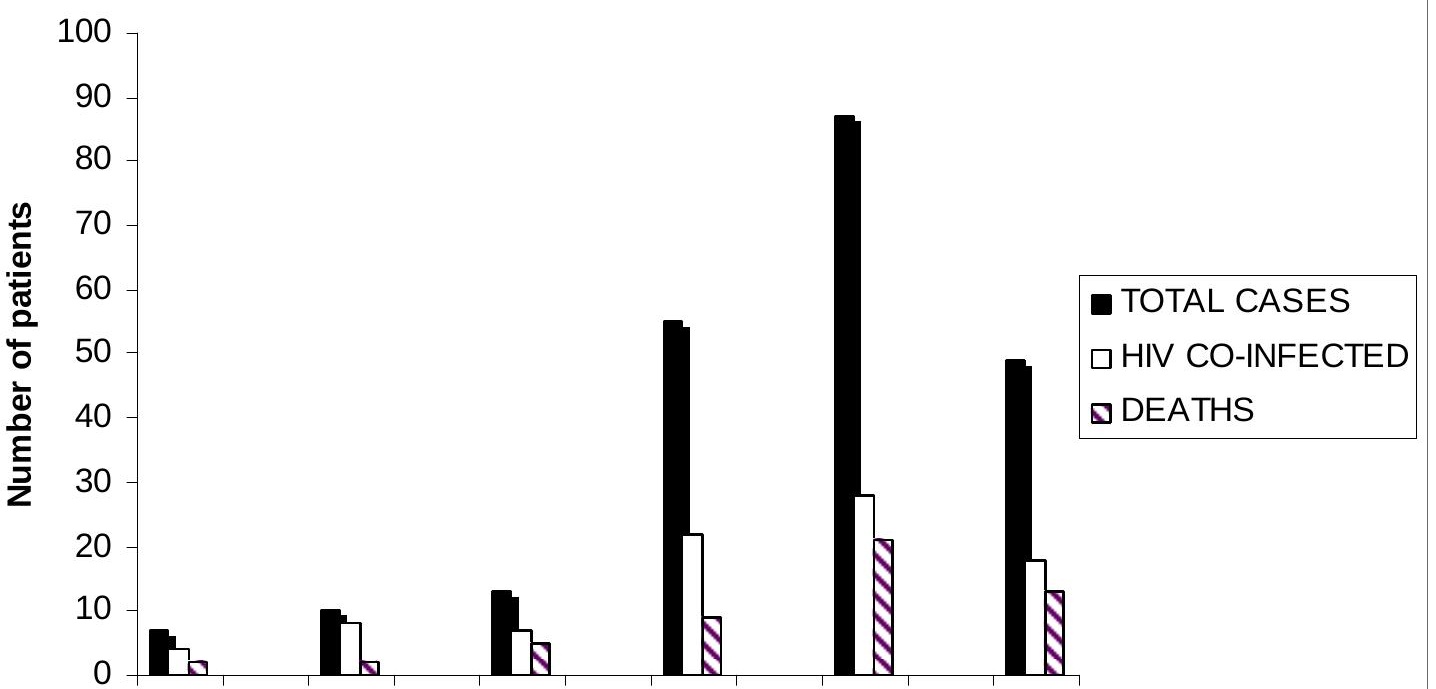


Figure 1: Visceral leishmaniasis, Gondar University Hospital, 1999-2004.

gum and gastrointestinal tract bleeding in different combinations. The least common clinical findings were coughing (32.6\%), gray to dark skin color change (24.4\%), diarrhea (21.7\%), lymphadenopathy (19.9\%) and jaundice $(6.3 \%)$ (Tables 2 \& 3 ).

The mean age of HIV co-infected patients was significantly higher than those without co-infection (29.3 \pm 8.8 vs $23.6 \pm 6.1$ years $\mathrm{T}=5.5, \quad \mathrm{P}<0.01)$. The average spleen size in HIV positive cases was smaller (9.0 $\pm 4.2 \mathrm{~cm}$ vs $11.0 \pm 4.7 \mathrm{~cm}, \mathrm{~T}+2.3, \mathrm{P}<0.05)$.
The mean hematocrit was significantly higher in those with HIV co-infection (23.5 $\pm 7.1 \%$ vs $21.2 \pm 6.0 \%$, $\mathrm{T}=2.5$, $\mathrm{P}<0.05)$. The mean differential count of neutrophils was higher $(59.1 \pm 14.6 \%$ vs $50.4 \pm 16.8, \mathrm{~T}=\mathrm{e} .8, \mathrm{P}<0.01)$, whereas the lymphocyte count was lower $(40.8 \pm 14.7 \%$ vs 48.5 $\pm 16.9, \mathrm{~T}=3.4, \mathrm{P}<0.01$ ) in VL cases with HIV coinfection compared to the lymphocyte count in HIV negative VL cases. The mean platelet count was $67.283 \pm 45,073 / \mathrm{mm}^{3}$. Likewise, the mean white cell count was $2,465 \pm 1,431 / \mathrm{mm}^{3}$ with a mean differential count of neutrophils and lymphocytes of $53.9 \pm 16.6 \%$ and 45.3 $\pm 16.5 \%$, respectively (Table 3).

Table 2: Clinical parameters in visceral leishmaniasis patients, Gondar University Hospital, Northwest Ethiopia, 1999-2004

\begin{tabular}{|c|c|c|c|c|}
\hline Clinical parameters & Number (\%) & HIV positive (\%) & HIV negative (\%) & P-value \\
\hline \multicolumn{5}{|l|}{ Symptoms } \\
\hline Body weakness & 221(100) & $87(100.0)$ & $125(100.0)$ & \\
\hline History of fever & $221(100.0)$ & $87(100.0)$ & $125(100.0)$ & \\
\hline Weight loss & $218(98.6)$ & $87(100.0)$ & $122(93.1)$ & \\
\hline Bleeding history & 119(53.8) & $47(54.0)$ & $66(52.8)$ & \\
\hline Loss of appetite & $60(27.3)$ & $21(24.1)$ & $34(27.2)$ & \\
\hline Cough & $82(37.1)$ & $34(39.1)$ & $48(38.4)$ & \\
\hline Diarrhoea & $48(21.7)$ & $20(23.0)$ & $28(22.4)$ & \\
\hline \multicolumn{5}{|l|}{ Signs } \\
\hline Splenomegaly & $221(100.0)$ & $87(100.0)$ & $125(100.0)$ & \\
\hline Pallor & $195(88.2)$ & $72(82.8)$ & $114(91.2)$ & \\
\hline Hepatomegaly & 104(47.1) & $38(43.7)$ & $62(49.6)$ & \\
\hline Skin change-gray/dark & $54(24.4)$ & $28(32.2)$ & 25(20.0) & 0.04 \\
\hline Lymphadenopathy & $44(19.9)$ & $22(25.3)$ & $22(17.6$ & \\
\hline Jaundice & $14(6.3)$ & $6(6.9)$ & $8(6.4)$ & \\
\hline
\end{tabular}

Table 3: Mean clinical \& laboratory values in visceral leishmaniasis patients with or without HIV co-infection, Gondar University hospital, 1999-2004

\begin{tabular}{|c|c|c|c|c|c|c|c|c|}
\hline \multirow[t]{2}{*}{ Parameters } & \multirow[t]{2}{*}{ Mean } & \multirow[t]{2}{*}{ S.D } & \multicolumn{2}{|c|}{ HIV positive } & \multicolumn{2}{|c|}{ HIV negative } & \multicolumn{2}{|c|}{$\begin{array}{l}\text { Significance of } \\
\text { difference }\end{array}$} \\
\hline & & & mean & S.D & mean & S.D & T-test & P-value \\
\hline Age (years) & 25.7 & 7.8 & 29.3 & 8.8 & 23.6 & 6.1 & 5.5 & 0.0000 \\
\hline Temperature $\left({ }^{0} \mathrm{C}\right)$ & 38.1 & 1.0 & 38.0 & 0.9 & 38.1 & 1.0 & 0.8 & 0.4 \\
\hline $\mathrm{BMI}\left(\mathrm{Kg} \cdot \mathrm{m}^{2}\right)$ & 15.5 & 2.4 & 15.5 & 2.6 & 15.4 & 2.3 & 0.3 & 0.8 \\
\hline Wight loss (kg) & 7.9 & 3.6 & 8.3 & 3.6 & 7.8 & 3.5 & 0.8 & 0.4 \\
\hline Spleen size $(\mathrm{cm})$ & 10.4 & 4.5 & 9.0 & 4.2 & 11.0 & 4.7 & 2.3 & 0.02 \\
\hline Total liver span (cm) & 14.4 & 1.5 & 14.2 & 1.4 & 14.5 & 1.6 & 0.9 & 0.4 \\
\hline Fever duration (weeks) & 12.6 & 8.9 & 13.1 & 9.7 & 12.4 & 8.4 & 0.5 & 0.6 \\
\hline Weight loss duration (weeks) & 13.4 & 10.1 & 14.8 & 11.9 & 12.3 & 8.5 & 1.7 & 0.08 \\
\hline White cell count $\left(\mathrm{No} / \mathrm{mm}^{3}\right)$ & 2465 & 1431 & 2,434 & 1139 & 2,543 & 1,619 & 0.5 & 0.6 \\
\hline Granulocytes (\%) & 53.9 & 16.6 & 59.1 & 14.6 & 50.4 & 16.8 & 3.8 & 0.0002 \\
\hline Lymphocytes (\%) & 45.3 & 16.5 & 40.8 & 14.7 & 48.5 & 16.9 & 3.4 & 0.0009 \\
\hline Hematocrit (\%) & 22.1 & 6.6 & 23.5 & 7.1 & 21.3 & 5.9 & 2.5 & 0.01 \\
\hline Platelet count $\left(\mathrm{No} / \mathrm{mm}^{3}\right)$ & 67,283 & 45,074 & 78,389 & 41.794 & 62,724 & 48,875 & 1.4 & 0.2 \\
\hline
\end{tabular}

Bivariate analysis identified 6 variables that were significantly associated with HIV co-infection: age $>20$ years, spleen size of $15 \mathrm{~cm}$ and below, hematocrit of $25 \%$ and above, granulocytes of $50 \%$ and below, lymphocytes at $50 \%$ and below, and dark to gray skin color change. Using a logistic regression model, only age $>20$ years was found to be an independent predictor of HIV coinfection $(\mathrm{OR}=3.2$, 95\% CI=1.6-6.3, $\mathrm{P}<0.001)$ (Table 4).

Sodium stibogluconate was given to 213(96.5\%) visceral leishmaniasis patients. Eight patients (3.6\%) were referred to other centers after diagnosis and stabilization, as the drug was not available in the hospital. From the 
treated cases, 157(73.7\%) were declared clinically cured, 52(24.4\%) died in the hospital and four reported back with relapse. All the relapse cases were HIV positive. The case fatality rate among HIV co-infected patients was $39.3 \%$, whereas it was $13.3 \%$ in HIV negatives patients (OR=2.1, CI=2.108.3). The mean hematocrit was significantly lower in those who died $(20.4 \pm 6.2 \%$ vs 22.6 $\pm 6.5, \quad \mathrm{~T}=2.1 \mathrm{P}<0.05)$. The mean age was significantly higher $(27.8 \pm 8.5$ vs $25.0 \pm 7.5$ year, $\mathrm{T}=2.2$,
$\mathrm{P}<0.05)$, while the mean body mass index was significantly lower $(14.4 \pm 2.5$ vs $15.8 \pm 2.3, \mathrm{~T}=3.8$, $\mathrm{P}<0.01)$ in those who died compared to those that were cured. Bleeding manifestation was significantly more common in those who died than in those who were cured ( $\mathrm{OR}=2.6,95 \%$ confidence interval=1.3-5.0, $\mathrm{P}<0.01)$. The same was true for manifestation of a dark/gray skin color change ( $\mathrm{Or}=2.0, \mathrm{CI}=1.0-3.9, \mathrm{P}<0.05)$.

Table 4: Characteristics associated with HIV co-infection in visceral leishmaniasis patients, Gondar University Hospital, 1999-2004

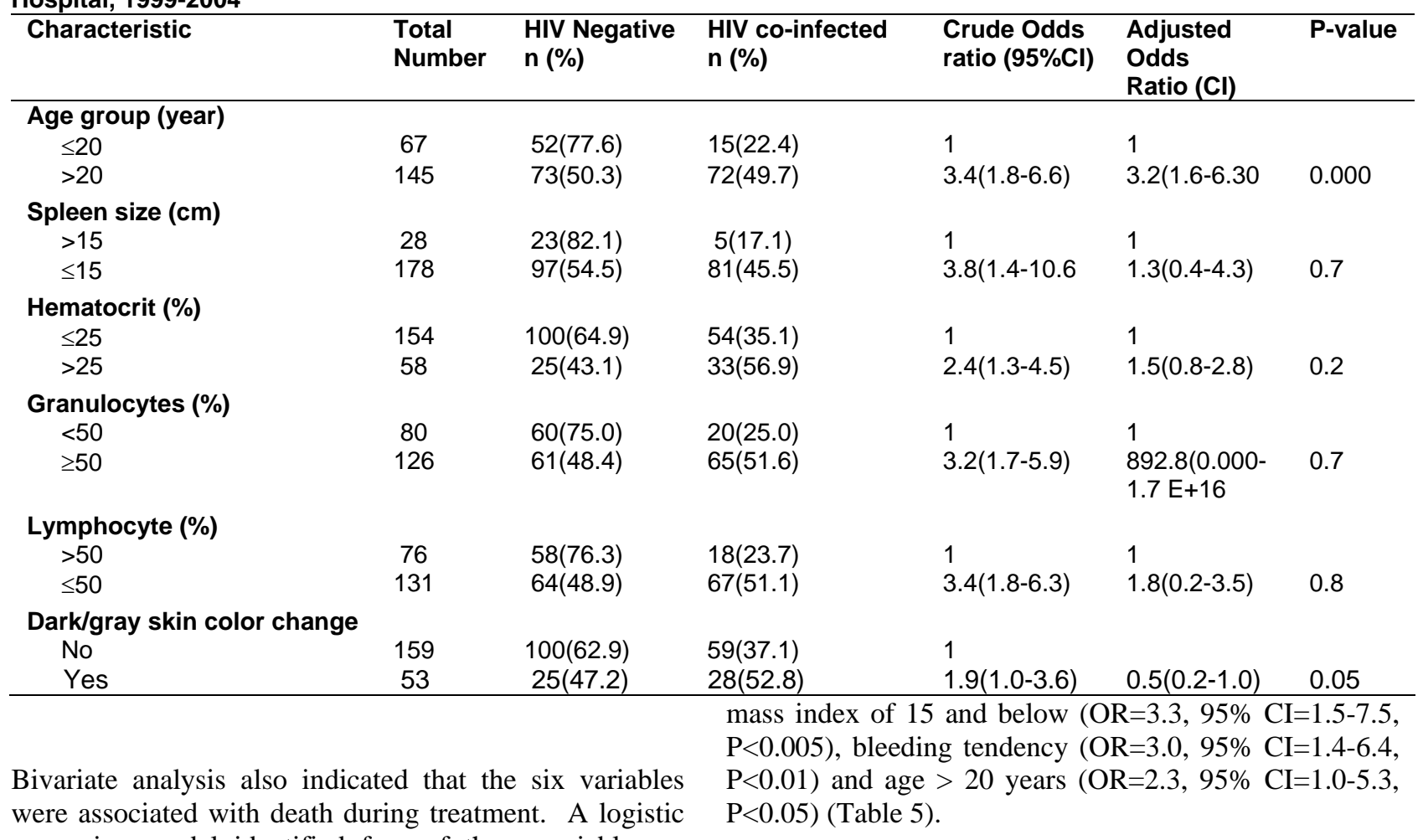
regression model identified four of these variables as independent predictors of mortality. These were HIV coinfection ( $\mathrm{OR}=4.2,95 \% \mathrm{CI}=2.8-8.9, \mathrm{P}<0.001)$, body

\begin{tabular}{|c|c|c|c|c|c|c|}
\hline Characteristic & $\begin{array}{l}\text { Total } \\
\text { Number }\end{array}$ & $\begin{array}{l}\text { Cured } \\
\text { No (\%) }\end{array}$ & Died n (\%) & $\begin{array}{l}\text { Crude Odds } \\
\text { ratio }(\mathrm{Cl})\end{array}$ & $\begin{array}{l}\text { Adjusted Odds } \\
\text { Ratio (Cl) }\end{array}$ & P-value \\
\hline \multicolumn{7}{|l|}{ HIV } \\
\hline Negative & 120 & $104(86.7)$ & 16(13.3) & 1 & 1 & 0.000 \\
\hline Positive & 84 & $51(60.7)$ & $33(39.3)$ & $4.2(2.1-8.3)$ & $42(2.0-8.9)$ & \\
\hline \multicolumn{7}{|l|}{ hematocrit (\%) } \\
\hline$>15$ & 179 & $141(78.8)$ & $38(21.2)$ & 1 & 1 & \\
\hline$\leq 15$ & 34 & $20(58.8)$ & $14(41.2)$ & $2.6(1.2-5.6)$ & $0.8(0.4-1.8)$ & 0.7 \\
\hline \multicolumn{7}{|c|}{ Age group (year) } \\
\hline$\leq 20$ & 71 & $62(87.3)$ & $9(12.7)$ & 1 & 1 & \\
\hline$>20$ & 142 & $99(69.7)$ & $43(30.3)$ & $3.0(1.4-6.6)$ & $2.3(1.0-5.3)$ & 0.049 \\
\hline \multicolumn{7}{|l|}{$\mathrm{BMI}\left(\mathrm{Kg} / \mathrm{m}^{2}\right)$} \\
\hline$>15$ & 122 & $103(84.4)$ & $19(15.6)$ & 1 & 1 & \\
\hline$\leq 15$ & 91 & $58(63.7)$ & $33(36.3)$ & $3.1(1.6-5.9)$ & $3.3(1.5-7.5)$ & 0.004 \\
\hline \multicolumn{7}{|l|}{ Bleeding } \\
\hline No & 97 & $83(84.5)$ & $15(15.5)$ & 1 & 1 & \\
\hline Yes & 116 & $79(68.1)$ & $37(31.9)$ & $2.6(1.3-5.0)$ & $3.0(1.4-6.4)$ & 0.005 \\
\hline \multicolumn{7}{|c|}{ Dark/gray skin color change } \\
\hline No & 161 & $18(34.6)$ & $34(65.4)$ & 1 & 1 & \\
\hline Yes & 52 & $34(21.1)$ & $127(78.9)$ & $2.0(1.0-3.9)$ & $1.7(0.8-3.7)$ & 0.2 \\
\hline
\end{tabular}

\section{Discussion}

The number and rate of admission of visceral leishmaniasis patients to Gondar University Hospital has shown an increasing pattern over time (Figure 1). Visceral leishmaniasis is a significant cause of mortality accounting for $3.6 \%$ of hospital deaths. There have been 
several epidemics of visceral leishmaniasis over the past few years in the neighboring country of Sudan which borders the two Ethiopian towns of Metema and Humera (20-23). Any ties between the epidemics in the two countries remain to be proven. Most of the patients in this study either came from, or had traveled to Metema and Humera as daily laborers, drivers, farmers, mobile merchants or soldiers. Rural-urban migration, agroindustrial and man-made projects like dams, irrigation systems and wells, as well as deforestation contribute to the spread of visceral leishmaniasis (2).

The high rate of HIV co-infection, which was $41 \%$ in our patients, is a major reason for such an increased morbidity and mortality from VL. The co-infection of leishmania and HIV is emerging as an extremely serious new disease and is increasingly frequent (24). The overlapping geographic distribution of visceral leishmaniasis and AIDS is increasing due to the spread of the main factors of AIDS transmission to suburban and rural areas of the world, and the simultaneous spread of visceral leishmaniasis from rural to suburban areas, complicated by mass migration, displacement, civil unrest, war and malnutrition (2, 8, and 25). Moreover, the immunological dysfunction caused by both leishmania and HIV augment the expression of one another. Dual infection plays an important role in the pathogenesis and disease progression of both. Both lieshmania and HIV exploit the immune regulatory networks of the host's immune system for their own progression. Co-infection with leishmania in HIV infected subjects can affect the course of either one, or both diseases and it clearly contributes to a vicious cycle of uncontrolled immunosupression and disease progression (17, 18, and 26). Immunological data indicate strong immunosupression of co-infected patients (27).

The association with deforestation, agricultureal occupations, cattle grazing and seasonal migration of farmers and daily laborers, could explain the preponderance of VL in males. Moreover, as women's access to the health services is limited, many cases of visceral leishmaniasis in women are likely to go undetected (7). Close to $98 \%$ of HIV co-infections were in males, similar to the 1997 WHO report in which $90 \%$ of 692 co-infected cases were males (24).

The productive age group (20-39 years) was most affected in this study. Visceral leishmaniasis adversely affects productivity and welfare (7). Similar to other studies, classic clinical manifestations of kala-azar such as fever, weight loss and cachexia, splenomegaly, and pancytopenia were evident in our patients $(8,19$, and 28$)$. Hepatomegaly was found in $47.1 \%$ of cases and history of bleeding in $53.8 \%$ of cases. Epistaxis accounted for 76.4 of the bleeding. Lymphadenopathy was found in $22 \%$ of the VL patients in this study, which is much lower than the 1991 \& 2002 studies from the Sudan, where it was in $84 \%$ and $86 \%$ of the patients respectively $(22,23)$.

Patients aged $>20$ years were more than 3 times as likely to have HIV infection as those 20 years and below. The clinical features of VL/HIV co-infected patients closely resemble those of VL in immuno-competent hosts (29). However, our HIV co-infected patients were found to have smaller spleen sizes, higher neutrophils, lower lymphocyte differential counts, a lesser degree of anemia, and dark/gray skin color change when compared to HIV negative patients.

In this study the over all case fatality rate was $24.4 \%$, which is much higher than the report of $6.4 \%$ from Sudan in 1991 (22). In 1978, the case fatality was 55.6\% among migrant agricultural laborers from the Metema and Humera areas admitted to the then Gondar Public Health College Hospital (10). In patients treated for visceral leishmaniasis, the reported case fatality rate can vary between $5 \%$ and $15 \%$ (25). In this study, the case fatality rate of HIV co-infected patients was 39.3\%, whereas it was $13.3 \%$ among HIV negative VL patients. Similar results were seen in the Sudan among non HIV infected VL patients $(21,22)$. The mortality rate in VL/HIV co-infected patients was very similar to the 2001 Ritmeijer report which observed a mortality rate of $33 \%$ among Ethiopian patients (30).

The HIV/VL co-infection has been called a deadly 'gridlock', as both infections tend to mutually reinforce their impact on the immune system (26). The overall high case fatality rate was explained by the high HIV seroprevalence in our study.

The HIV epidemic induced a major change in the epidemiology and treatment outcome of VL. As of 2000, Leishmania and HIV co-infections had been reported from 33 countries (26). Efficient case management based on early diagnosis and treatment is the key to limiting morbidity and preventing mortality (7). However, in this study, patients sought treatment late in the course of their illness as they came from distant and inaccessible areas, resulting in terminal complications of VL. This might have its own impact on the treatment outcome. Moreover, the optimal medications and intensive care facilities were not available in the hospital.

Although follow-up at 3 and 6 months was arranged for all treated cases, only 4 relapsed cases, all of which were co-infected with HIV, showed up for follow up visits. The relapse rate has been reported to be as high as $50 \%$ in HIV co-infected individuals $(7,13)$. The inability of the antibody response to control the parasite, and the absence of specific T-cell immunity to leishmania species can explain the high number of relapses (32).

Using logistic regression, the independent variables predicting mortality were: age $>20$ years, bleeding tendency, BMI of 15 and below, and HIV co-infection, in increasing order. Patients aged $>20$ years were more than twice as likely to die of VL as those 20 years and below. Visceral leishmaniasis cases with bleeding (at least once) were 3 times as likely to die as those with no bleeding. Individuals with body mass index of less than 15 were more than 3 times as likely to die as those with BMI of 15 and above. HIV co-infected visceral leishmaniasis patients were more than 4 times as likely to die as HIV negative patients. Hemorrhage, low body mass index and HIV co-infection were also among the 
predicators of death in Ethiopian VL patients, as was previously reported (16).

\section{Conclusion and recommendation}

The number of visceral leishmaniasis patients admitted to Gondar University Hospital increased dramatically from year to year in the five year period this study covered. HIV co-infection and related case fatality rates were high. HIV co-infection was prominent and was the most significant independent factor contributing to high mortality from VL. We recommend a prospective case control study and critical care in treatment of HIV/VL co-infection, as it is a unique clinical entity.

\section{Acknowledgement}

We thank Prof. Asrat Hailu from the Department of Microbiology and Parasitology of Addis Ababa University Faculty of Medicine for his support and encouragement. Our appreciation goes to Ato Afework Kassu who was the head of the research and publication office of Gondar College for supporting us in all aspects and to Dr. Alemayehu Worku in the Department of community Health of Addis Ababa University for the statistical consultation. Our gratitude goes to MSFHolland for supplying the drugs for the patients. The research and publication office of Gondar University is acknowledged for allowing and supporting the study.

\section{References}

1. World Health Organization. The world health report 2000 health systems: improving performance, Geneva the Organization 2000; also available at URL: http://www who-int/htr.

2. World Health Organization, the Leishmaniasis and leishmania/ HIV Co-infection, Fact sheet No 116 May 2000.

3. Desjeux P. Leishmaniasis, public health aspects and control. Clin Dermatol 1996;14:417-423.

4. Arias JR; Monteiro P, Zicker F, The reemergence of visceral leishmaniasis in Brazil. Emerg Infect Dis 1996;2:145-146.

5. Alvar J. et al. Leishmaniasis and human immunodeficiency virus Co- infection, the first 10 years Clin Microbiol Rev 1997;10:298-319.

6. Murray HW. Clinical and experimental advances in treatment of Visceral Leishmaniasis; Antimicrob Agents Chemother. 2001;45(8):2185-2197.

7. Guerin J P, Olliaro P, Sundar S, Boelaert M, Croft L S, Desjeux P, et al: Visceral leishmaniasis: current status of control, diagnosis and treatment and proposed research and development agenda; Lancet Infect Dis, 2002;2(8):1-9.

8. Herwaldt BL Leishmaniasis, Seminar. Lancet 1999;354:1191-1199.

9. World Health Organization, the world health report, 2001, Geneva, WHO 2001.

10. Mengesha B, and Abuhoy M., Kala-azar among Labor migrants in Metema- Humera region of Ethiopia. Trop geogr Med 1978;30:199-206.

11. P. Desjeux: Information on the epidemiology and control of the leishmaniases by country or territory; WHO/LEISH/ 91.30: 10-11.

12. Hailu A. \& Berhe N. The performance of direct agglutination test (DAT) in the diagnosis of visceral leishmaniasis among Ethiopian patients with HIV
Co-infection; Ann Trop Med Parasitol 2002;96(1): 25-30.

13. Anema A and Ritmeijer K, Treating HIV/AIDS and leishmaniasis co-infection in Ethiopia; JAMC; 2005; 172(11):1434-1435.

14. World Health Organization; Dramatic Upsurge in Visceral Leishmaniases cases in the horn of Africa, 1998 Press release WHO/23.

15. Berhe N. Hailu A,Wolday D, Negesse Y, Cenini P, and Frommel D; Ethiopian visceral leishmaniasis patients co-infected with human immunodeficiency virus; Trans R Soc Trop Med Hyg 1995;89:205-207.

16. Veeken $H$. Control of infectious diseases in developing countries; field studies on visceral leishmaniasis and meningitis; 2001; Thesis pp 74-94.

17. Berhe N, Wolday D, Hailu A, Abraham Y, Ali A, Gebre-Michael T, Desjeux P, Sonnerborg A, Akuffo $\mathrm{H}$, Britton $\mathrm{S}$ et al viral load and response to antileishmanial chemotherapy in co-infected patients. AIDS 1999;13(14):1921-1025.

18. Wolday D, Berhe $\mathrm{N}$, Akuffo $\mathrm{H}$, and Britton S: Leishmania - HIV interaction; immunopathogentic mechanisms; Parasitol Today; 1999;15(5):182-187.

19. Pearson R D, Sousa A D: Clinical spectrum of leishmaniasis: state-of-the-art clinical article; Clin Infect Dis 1996;22:1-13.

20. Beer P D, Harith A E, Deng L L, Semiao-Santos S J, Chantal B and Groothest M V; A killing disease epidemic among displaced Sudanese population identified as visceral leishmaniasis Am J Trop Med Hyg 1991;44(3):283-289.

21. Zijlstra EE, Ali MS, El-Hassan AM, El-Toumia, Satti M, and Ghalib HW; Clinical aspects of kala azar in children from the Sudan: a comparison with the disease in adults; J Trop Pediatr 1992;38:17-21.

22. Zijlstra EE, Ali MS, El-Hassan AM, El-ToumIA, Satti M, Ghalib HW, SondorpE, and Winkler A; Kala-azar in displaced people from southern Sudan; epidemiological, clinical and therapeutic findings Trans R Soc Trop Med Hyg 1991;85:365-369.

23. El-Safi SH, Bucheton B, Kheir MM, Musa HA, ElObaid M, Hammad A, and Dessein A; Epidemiology of Visceral leishmaniasis in Atbara River area, eastern Sudan: the outbreak of Barbar El Fugara village 1996-1997; Microbes Infect; 2002;4:14391447.

24. World Health Organization Weekly Epidemiological Record; World health organization Geneva 1997; 72(8):49-56.

25. Boelaert M, Criel B, Leeuwenburg J, Van Damme W, Le Ray D and Van der Stuyft P Visceral leishmaniasis Control: a public health perspective Trans R Soc Trop Med Hyg; 2000;94:465-471.

26. World Health Organization; Leishmania and HIV in gridlock, Geneva; World health organization WHO/CTD/LEISH/98.9.

27. Gradoni L; Scalone A, Gramiccia M, and Troiani M, Epidemiological Surveillance of leishmaniasis in HIV-1 infected individuals in Italy; AIDS; 1996;10: 785-791.

28. Manson-Bahr P.E.C.and Heish RB Studies in leishmaniasis in East Africa: clinical features and treatment, Trans R Soc Trop Med Hyg 1956;50(5): 465-71. 
29. Russo R, Laguna F, Lopez-Velez R, Medrano FJ, Rosenthal E, Cacopardo B, and Nigro L; Viscera leishmaniasis in those infected with HIV: Clinical aspects and other opportunistic infections; Ann Trop Med Parasitol 2003;97(s1):s99-s105.

30. Ritmeijer K, Veeken H, Melaku Y, Leal G, Amsalu R, Seaman J, and Davidson RN; Ethiopian kala-azar: generic sodium stibogluconate and Pentostam are equivalent; HIV co- infected patients have a poor outcome; Trans R Soc Trop Med Hyg 2001;95(6): 668-672.

31. Rosenthal E, Marty P, Poizot-Martin I, Reynes J, Pratlong F, Lafeuillade A, Jaubert D, Boulat O, Dereure J, Gambarelli F, Gastaut J, Dujardin P, Dellamonica $\mathrm{P}$ and Cassuto J; visceral leishmaniasis and HIV-1 co-infection in Southern France; Trans R Soc Trop Med Hyg; 1995;89:159-162.

32. Moreno J, Canavate C, Chamizo C, Laguna F, and Alvar J; HIV-leishmania infantum co-infection: Humoral and cellular immune responses to the parasite after chemotherapy; Trans R Soc Trop Med Hyg 2000;94:328-332. 